\title{
Letter to the Editor: Comparison of Outcomes with Semi- mechanical and Circular Stapled Intrathoracic Esophagogastric Anastomosis Following Esophagectomy
}

\author{
Victor D. Plat ${ }^{1} \cdot$ Donald L. van der Peet ${ }^{1}$
}

Published online: 22 October 2019

(C) Société Internationale de Chirurgie 2019

We would like to congratulate Yanni and the co-authors on their clinically relevant article which was published in the World Journal of Surgery [1]. They evaluated surgical outcomes of a semi-mechanical and circular stapled anastomosis for patients undergoing an Ivor Lewis esophagectomy. Anastomotic leakage was observed in 13 out of 85 patients $(15 \%)$ following a circular stapled anastomosis and in 3 out of 74 patients (4\%) following a semi-mechanical technique, which appeared to be a significant difference. Their presented results are encouraging, as anastomotic leakage remains the primary source of morbidity and mortality following esophagectomy. Nevertheless, after reading the results we have a few questions we would like them to address.

The authors acknowledge significant limitations in their study, e.g., limited numbers of patients and a change in technique during their study. It would be helpful if the authors could elaborate on the reasons why they changed their preferred technique in the course of the study.

The reported leakage rate of $15 \%$ following a circular stapled reconstruction is relatively high as current evidence suggests a rate of approximately $4-7 \%$ in specialized centers [2-4]. As no other studies have demonstrated the superiority of linear stapling in preventing anastomotic leakage, we wonder if the authors could point out why this was the case in their study $[2,5]$ ?

Finally, we noticed that some of the data in Tables 1 and 2 are missing. This makes it difficult for the reader to interpret the studied population and to reproduce these successful results.

In conclusion, we want to thank Yanni and colleagues on addressing a very relevant subject and look forward to receiving more information and feedback concerning our remarks.

\section{References}

1. Yanni F, Singh P, Tewari N et al (2019) Comparison of outcomes with semi-mechanical and circular stapled intrathoracic esophagogastric anastomosis following esophagectomy. World J Surg 43:1-7. https://doi.org/10.1007/s00268-019-05057-0

2. Zhou D, Liu QX, Deng XF et al (2015) Comparison of two different mechanical esophagogastric anastomosis in esophageal cancer patients: a meta-analysis. J Cardiothorac Surg 10:67

3. Luketich JD, Pennathur A, Awais O et al (2012) Outcomes after minimally invasive esophagectomy: review of over 1000 patients. Ann Surg 256:95-103

4. Honda M, Kuriyama A, Noma $\mathrm{H}$ et al (2013) Hand-sewn versus mechanical esophagogastric anastomosis after esophagectomy: a systematic review and meta-analysis. Ann Surg 257:238-248

5. Deng XF, Liu QX, Zhou D et al (2015) Hand-sewn vs linearly stapled esophagogastric anastomosis for esophageal cancer: a meta-analysis. World J Gastroenterol 21:4757-4764

Publisher's Note Springer Nature remains neutral with regard to jurisdictional claims in published maps and institutional affiliations.

Victor D. Plat

V.plat@amsterdamumc.nl

1 Department of Gastrointestinal Surgery, Amsterdam UMC, VU University Medical Center, Amsterdam, The Netherlands 